\title{
Profile of ustekinumab and its potential in patients with moderate-to-severe Crohn's disease
}

This article was published in the following Dove Press journal:

Clinical and Experimental Gastroenterology

23 May 2014

Number of times this article has been viewed

\section{Anne Tuskey \\ Brian W Behm \\ Division of Gastroenterology and Hepatology, University of Virginia School of Medicine, Charlottesville, VA, USA}

Correspondence: Anne Tuskey Division of Gastroenterology and Hepatology, University of Virginia School of Medicine, 1215 Lee Street, Charlottesville, VA 22908, USA

$\mathrm{Tel}+\mathrm{I} 4342439309$

Fax +I 4342447527

Email agt2w@virginia.edu

\begin{abstract}
The advent of anti-tumor necrosis factor (TNF)- $\alpha$ therapy has been a major advance in the medical management of Crohn's disease (CD). However, a significant proportion of patients with $\mathrm{CD}$ do not respond adequately to treatment with these agents. Primary and secondary nonresponse to anti-TNF $\alpha$ therapy represents a common clinical challenge, and highlights the need for the development of additional medication options for $\mathrm{CD}$. The proinflammatory cytokines interleukin (IL)-12 and IL-23 are thought to play a key role in the pathogenesis of CD, and serve as a potential target for additional biologic therapies. Monoclonal antibodies targeting IL-12/23 have shown efficacy in animal models of colitis, and are currently being studied in Phase III clinical trials of CD. This review focuses on ustekinumab, a fully human immunoglobulin $\mathrm{G}_{1}$ monoclonal antibody, which blocks activity of IL-12 and IL-23 through binding the p40 subunit, and describes the current efficacy and safety data for ustekinumab in patients with CD.
\end{abstract}

Keywords: Crohn's disease, ustekinumab, clinical trials, inflammatory bowel disease

\section{Introduction to Crohn's disease and current treatment options}

Crohn's disease (CD) is a chronic inflammatory disorder of the gastrointestinal tract that is characterized by recurrent relapses and periods of remission. Current therapies are aimed at inducing and maintaining remission and improving quality of life (QOL), while minimizing adverse effects of pharmacologic therapy. Historically, corticosteroids were used as first-line therapy to manage symptoms, but were associated with a high incidence of steroid dependency and unacceptable rates of adverse events. ${ }^{1}$ Furthermore, while corticosteroids are useful to induce symptomatic remission, they do not promote mucosal healing and are not useful for maintenance of remission. ${ }^{1,2}$ Methotrexate and thiopurines (6-mercaptopurine and azathioprine) were found to be effective as steroidsparing agents and for maintenance of remission in $\mathrm{CD},{ }^{3-5}$ but have a delayed onset of action and are only effective in $60 \%-70 \%$ of patients who receive them. ${ }^{4,5}$ More recently, the tumor necrosis factor (TNF)- $\alpha$ antagonists infliximab and adalimumab have been shown to be effective for the induction and maintenance of remission in patients with moderate-to-severe $\mathrm{CD}$, while certolizumab pegol is effective for the maintenance of remission in patients who have responded to certolizumab-induction therapy. ${ }^{6-12}$ This class of medication is currently the most effective treatment option available for $\mathrm{CD} .{ }^{13}$

\section{Problems with nonresponders}

While anti-TNF $\alpha$ therapies have been a significant advance in the management of CD, significant proportions (up to $40 \%$ ) of patients do not respond to induction therapy 
(primary nonresponders). ${ }^{14}$ Among patients who respond to induction therapy with an anti-TNF $\alpha$ agent, almost half lose response and/or develop hypersensitivity reactions (secondary nonresponders). ${ }^{15}$ Patients with a primary nonresponse are unlikely to benefit from switching to a second anti-TNF $\alpha$ agent. Patients who develop a secondary nonresponse to an anti-TNF $\alpha$ agent also have lower response rates when switching to a second or third anti-TNF $\alpha$ agent. ${ }^{16}$ This represents a common but challenging clinical problem, and emphasizes the need for additional therapies for the management of these patients.

\section{Review of pharmacology, mode of action, pharmacokinetics of ustekinumab}

The interleukin (IL)-12 family of cytokines, which includes IL-22, IL-23, IL-25, and IL-27, is responsible for the differentiation of T-helper (Th) cells into cytotoxic Th1 cells. ${ }^{17-19}$ Inflammatory changes in CD are associated with excess cytokine activity driven by activated Th1 cells. ${ }^{20,21}$ Accordingly, IL-12 and IL-23 have been linked to the pathophysiology of CD as well as other immune-mediated disorders, including psoriasis, psoriatic arthritis, and multiple sclerosis. $^{21-23}$ IL-12 and IL-23 are heterodimeric proteins composed of a unique subunit (p35 or p19, respectively) covalently linked to a shared p40 subunit. ${ }^{19,24}$ IL-12 induces differentiation of naïve cluster of differentiation (CD) $4^{+} \mathrm{T}$ cells into interferon- $\gamma$-producing Th1 cells, which mediate cellular immunity. IL-23 induces differentiation of naïve $\mathrm{CD}^{+} \mathrm{T}$ cells into Th17 cells, which produce several proinflammatory cytokines to also mediate cellular immunity. ${ }^{19,25,26}$ Therefore, inhibiting IL-12 and IL-23 inflammation pathways could potentially be a unique target for therapy in CD.

Ustekinumab (CNTO-1275, Stelara ${ }^{\circledR}$; Janssen Biotech, Horsham, PA, USA) is a humanized immunoglobulin $\mathrm{G}_{1} \kappa$ monoclonal antibody, which binds with high affinity and specificity to the shared p40 subunit of IL-12 and IL-23. This binding blocks the interaction of both IL-12 and IL-23 with their receptor IL-12R $\beta 1,{ }^{26,27}$ and results in a diminution of immune-cell activation by inhibiting the action of $\mathrm{T}$ cells. Ustekinumab can be given intravenously (IV) or subcutaneously (SC) as a weight-based infusion or a fixed-dose injection. The median half-life of ustekinumab is approximately 3 weeks, and exposure is increased in a dose-proportional manner. ${ }^{28}$ The pharmacokinetic profile is affected by body weight, but not by age. ${ }^{28}$ Ustekinumab is currently approved by the US Food and Drug Administration for the treatment of psoriasis ${ }^{29-31}$ and psoriatic arthritis. ${ }^{32,33}$

\section{Efficacy studies, including any comparative studies}

The first study evaluating ustekinumab in CD was published in 2008. ${ }^{26}$ The multicenter trial included two populations. Population 1 included 104 patients with moderate-to-severe CD enrolled in a double-blind, placebo-controlled, parallelgroup, crossover study. Patients were randomized into one of four groups: SC placebo at weeks $0,1,2$, and 3, then $90 \mathrm{mg}$ ustekinumab at weeks 8, 9, 10 and 11; SC $90 \mathrm{mg}$ ustekinumab at weeks $0,1,2$, and 3 , then placebo at weeks $8,9,10$, and 11; IV placebo at week 0 , then $4.5 \mathrm{mg} / \mathrm{kg}$ ustekinumab at week 8 ; or IV $4.5 \mathrm{mg} / \mathrm{kg}$ ustekinumab at week 0 , then placebo at week 8 . Population 2 comprised 27 patients who were either nonresponders to a three-dose infliximab $5 \mathrm{mg} / \mathrm{kg}$ induction (primary nonresponders) or initial responders who lost response during maintenance therapy every 8 weeks (secondary nonresponders). Population 2 patients were enrolled in an open-label study, and were randomized to either SC $90 \mathrm{mg}$ ustekinumab at weeks 0,1 , 2 , and 3 or IV $4.5 \mathrm{mg} / \mathrm{kg}$ ustekinumab at week 0 . The primary end point, a reduction of at least $25 \%$ and 70 points from the baseline CD Activity Index (CDAI) at week 8 in population 1 , was not met in this study; clinical response was achieved in 25 of 51 patients $(45 \%)$ in the combined ustekinumab group compared to 21 of 53 patients $(40 \%)$ in the placebo group at week $8(P=0.34)$. However, in a subgroup analysis of 49 patients previously treated with infliximab, the rates of clinical response to ustekinumab were significantly greater than those for placebo through 8 weeks (Figure 1).

The high placebo-response rate in this study is notable, as it impacts the ability to detect an overall treatment effect for ustekinumab. For population 2, numerically higher rates

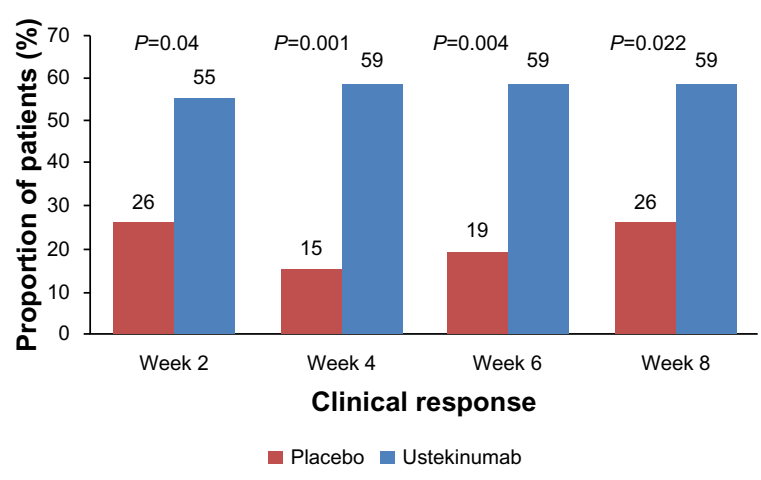

Figure I Phase II A subgroup analysis evaluating clinical response to ustekinumab or placebo in Crohn's patients with prior anti-tumor necrosis factor- $\alpha$ exposure. Note: Reprinted from Gastroenterology, 135, Sandborn WJ, Feagan BG, Fedorak RN, et al, A randomized trial of ustekinumab, a human interleukin- I2/23 monoclonal antibody, in patients with moderate-to-severe Crohn's disease, ||30-||4|, Copyright (2008), with permission from Elsevier. ${ }^{26}$ 
of clinical response and remission were seen with IV administration of ustekinumab compared to SC administration out to week $8,{ }^{26}$ but this did not achieve statistical significance.

The results of a Phase IIB 36-week, randomized, double-blind, placebo-controlled trial of ustekinumab in CD were reported in 2012. ${ }^{16}$ The study population comprised 526 patients with moderate-to-severe CD who were previously resistant to TNF $\alpha$ inhibitors. TNF $\alpha$ resistance was defined as a primary nonresponse, secondary nonresponse, or unacceptable side effects after receiving a TNF $\alpha$ antagonist at an approved dose.

During the 8-week induction phase, patients were randomly assigned to ustekinumab 1, 3, or $6 \mathrm{mg} / \mathrm{kg}$ IV or placebo. At week 8 , ustekinumab responders and nonresponders underwent a separate randomization to receive either SC ustekinumab $90 \mathrm{mg}$ or placebo at weeks 8 and 16. Likewise, patients who responded to placebo induction received SC placebo at weeks 8 and 16, while patients who did not respond to placebo induction received SC ustekinumab $270 \mathrm{mg}$ at week 8 followed by $\mathrm{SC}$ ustekinumab $90 \mathrm{mg}$ at week 16. Efficacy was then assessed for all patients - ustekinumab responders and nonresponders as well as placebo responders and nonresponders - at week 22 , and all patients were followed through week 36 for safety analysis. The primary end point was a clinical response $(>100-$ point decrease from baseline CDAI) at week 6 .

The primary study end point was achieved in significantly more patients who received $6 \mathrm{mg} / \mathrm{kg}$ of IV ustekinumab at 6 weeks compared to those who received placebo $(39.7 \%$ versus $23.5 \%, P=0.005)$. The difference was not statistically significant with the $3 \mathrm{mg} / \mathrm{kg}$ ustekinumab dose (34.1\% versus $23.5 \%, P=0.06$ ) and there was not a clear dose response (Figure 2). The proportion of patients in clinical remission (CDAI score $<150$ ) at weeks 6 and 8 was not significantly different between patients treated with ustekinumab and those treated with placebo $(12.2 \%$ in the $6 \mathrm{mg} / \mathrm{kg}$ ustekinumab versus $10.6 \%, P=0.68$ at week 6 ; and $18.3 \%$ versus $10.6 \%$, $P=0.07$ at week 8). The median baseline CDAI score was 333. This high numeric value at baseline likely impacted the ability to achieve clinical remission by week 8 in the study. Of the patients who responded to ustekinumab induction, the proportion of patients with maintained response at 22 weeks was significantly greater in the ustekinumab group compared to the placebo group (69.4\% versus $42.5 \%, P<0.001)$. There were also significantly higher rates of clinical remission at week 22 with ustekinumab (41.7\% versus $27.4 \%, P=0.03)$ (Figure 3).

Three additional trials involving ustekinumab in CD are currently being performed (Table 1). The first trial (UNITI-1 [A Study to Evaluate the Safety and Efficacy of Ustekinumab in Patients with Moderately to Severely Active Crohn's Disease Who Have Failed or Are Intolerant to Tumor Necrosis Factor \{TNF\} Antagonist Therapy]) is a Phase III multicenter randomized placebo-controlled trial evaluating ustekinumab $(6 \mathrm{mg} / \mathrm{kg} \mathrm{IV}, 130 \mathrm{mg} \mathrm{SC})$ or placebo in patients with moderateto-severe CD with prior anti-TNF $\alpha$ exposure. ${ }^{34}$ This study has completed enrollment, although trial results have not yet been reported. Two other studies, an induction trial (UNITI-2 [A Study to Evaluate the Safety and Efficacy of Ustekinumab

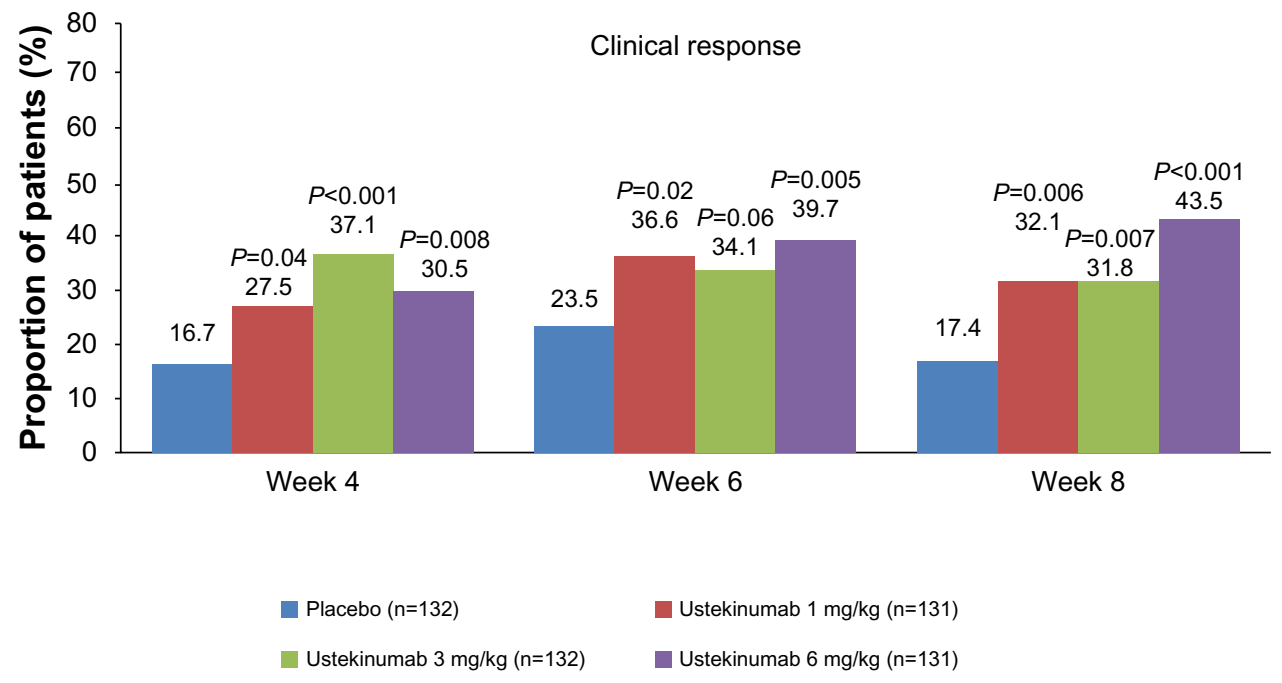

Figure 2 Phase IIB trial evaluating clinical response to ustekinumab in patients with Crohn's disease with prior primary or secondary nonresponse to anti-tumor necrosis factor- $\alpha$ therapy.

Note: From N Engl J Med, Sandborn WJ, Gasink C, Gao LL, et al, Ustekinumab induction and maintenance therapy in refractory Crohn's disease, 367, I5I9-I528, copyright (c) (2012) Massachusetts Medical Society. Reprinted with permission from Massachusetts Medical Society. ${ }^{16}$ 


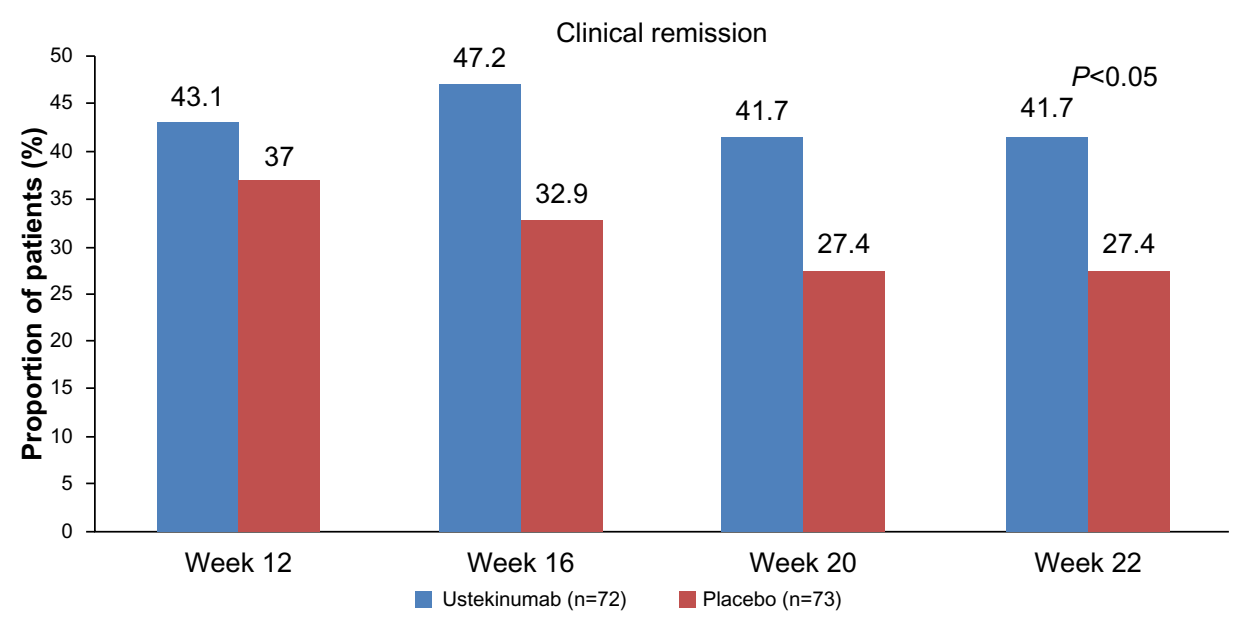

Figure 3 Clinical remission in anti-tumor necrosis factor- $\alpha$-exposed Crohn's patients with an initial response to ustekinumab.

Note: From N Engl J Med, Sandborn WJ, Gasink C, Gao LL, et al, Ustekinumab induction and maintenance therapy in refractory Crohn's disease, 367, I5I9-I528, copyright (c) (2012) Massachusetts Medical Society. Reprinted with permission from Massachusetts Medical Society. ${ }^{16}$

Induction Therapy in Patients With Moderately to Severely Active Crohn's Disease]) $)^{35}$ and a maintenance trial (IM-UNITI [A Study to Evaluate the Safety and Efficacy of Ustekinumab Maintenance Therapy in Patients With Moderately to Severely Active Crohn's Disease]) evaluating ustekinumab, are currently enrolling patients, and no preliminary data are available from these studies. ${ }^{36}$

Table I Phase III studies evaluating ustekinumab in Crohn's disease (CD)

\begin{tabular}{|c|c|c|c|}
\hline Study & Description & $\begin{array}{l}\text { Study } \\
\text { end point }\end{array}$ & Status \\
\hline UNITI-I ${ }^{34}$ & $\begin{array}{l}\text { Randomized placebo-controlled } \\
\text { trial evaluating ustekinumab in } \\
\text { moderate-to-severely active CD } \\
\text { with prior failure or intolerance } \\
\text { to anti-TNF } \alpha \text { therapy }\end{array}$ & $\begin{array}{l}\text { Clinical } \\
\text { response, } \\
\text { week } 6\end{array}$ & $\begin{array}{l}\text { Completed, } \\
\text { results } \\
\text { pending }\end{array}$ \\
\hline UNITI-2 ${ }^{35}$ & $\begin{array}{l}\text { Randomized placebo-controlled } \\
\text { trial evaluating ustekinumab } \\
\text { in moderate-to-severely active } \\
\text { CD without prior failure } \\
\text { or intolerance to anti-TNF } \alpha \\
\text { therapy }\end{array}$ & $\begin{array}{l}\text { Clinical } \\
\text { response, } \\
\text { week } 6\end{array}$ & Recruiting \\
\hline IM-UNITI ${ }^{36}$ & $\begin{array}{l}\text { Randomized placebo-controlled } \\
\text { trial evaluating safety and } \\
\text { efficacy of ustekinumab in CD } \\
\text { patients with clinical response } \\
\text { in UNITI-I or UNITI-2 }\end{array}$ & $\begin{array}{l}\text { Clinical } \\
\text { remission, } \\
\text { week } 44\end{array}$ & Recruiting \\
\hline
\end{tabular}

Abbreviations: TNF, tumor necrosis factor; UNITI-I, A Study to Evaluate the Safety and Efficacy of Ustekinumab in Patients with Moderately to Severely Active Crohn's Disease Who Have Failed or Are Intolerant to Tumor Necrosis Factor (TNF) Antagonist Therapy; UNITI-2, A Study to Evaluate the Safety and Efficacy of Ustekinumab Induction Therapy in Patients With Moderately to Severely Active Crohn's Disease; IM-UNITI, A Study to Evaluate the Safety and Efficacy of Ustekinumab Maintenance Therapy in Patients With Moderately to Severely Active Crohn's Disease.

\section{Safety and tolerability}

Safety data for ustekinumab are available for more than 3,000 patients enrolled in clinical trials evaluating use of the drug in psoriasis, psoriatic arthritis, multiple sclerosis, and CD. ${ }^{19}$ In the two published CD trials, the proportion of patients with at least one adverse event through week 8 was slightly higher in the placebo group (Phase IIA) and similar among the study groups (Phase IIB). ${ }^{16,26}$ In the Phase IIA study in CD, serious adverse events occurred in three of 53 patients $(6 \%)$ in the placebo group compared to two of 51 patients $(4 \%)$ in the ustekinumab group through week 8 . No serious infections or opportunistic infections were reported during this time. Twelve patients (23\%) in the placebo group experienced one or more infections compared to eight patients (15\%) in the ustekinumab group. ${ }^{26}$ Administration-site reactions occurred more commonly in the SC placebo group (4\%) than the SC ustekinumab group (0\%). ${ }^{26}$ Mild adverse events occurring within 1 hour of IV administration, including fever, flushing, and pruritus, were more common in the IV ustekinumab group (19\%) compared to the IV placebo group $(0 \%){ }^{26}$ Adverse events were recorded through 28 weeks, and six patients $(6 \%)$ in population 1 experienced one or more serious adverse events (worsening CD in two patients, small intestinal obstruction in two patients, colonic stenosis and pneumothorax in one patient, and prostate cancer in one patient), and four patients $(15 \%)$ in population 2 experienced one or more serious adverse events (viral gastroenteritis in one patient, worsening $\mathrm{CD}$ in one patient, nephrolithiasis in one patient, and worsening $\mathrm{CD}$, syncope, and disseminated histoplasmosis in one patient). The histoplasmosis occurred in a patient who had discontinued infliximab $10 \mathrm{mg} / \mathrm{kg} 3$ months prior to study 
entry, and received IV ustekinumab, azathioprine, and prednisone concomitantly. ${ }^{26}$ Two population 1 patients developed malignancy: prostate cancer was diagnosed 2 months after receiving IV ustekinumab in a patient with elevated prostatespecific antigen levels prior to enrollment, and squamous and basal skin cancers were diagnosed in a patient approximately 6 months after SC ustekinumab. ${ }^{26}$ No tuberculosis or hematologic malignancies were reported during the study. ${ }^{24}$

In the Phase IIB study, serious infections occurred in five patients who received $6 \mathrm{mg} / \mathrm{kg}$ ustekinumab (Clostridium difficile, viral gastroenteritis, urinary tract infection, anal abscess, and vaginal abscess), in one patient who received $1 \mathrm{mg} / \mathrm{kg}$ of ustekinumab (central line staphylococcal infection), and in one patient who received placebo (anal abscess) during the 8 -week induction phase. ${ }^{16}$ Patients were followed for approximately 25 weeks in the maintenance phase, with similar reported rates of serious adverse events as seen in the ustekinumab and placebo groups. No deaths, major cardiovascular events, tuberculosis, or other serious opportunistic infections were reported. ${ }^{16}$ One patient treated with $1 \mathrm{mg} / \mathrm{kg}$ IV ustekinumab followed by $90 \mathrm{mg}$ SC ustekinumab at weeks 8 and 16 developed a basal cell carcinoma. ${ }^{16}$ There were no other malignancies reported during the study.

While safety data in the CD population have thus far only been reported through 28 weeks of follow-up, long-term data are available from trials of ustekinumab in patients with psoriasis. The longest follow-up was 5 years in patients with moderate-to-severe psoriasis in PHOENIX 1 (A Study of Safety and Effectiveness of Ustekinumab [CNTO 1275] in Patients with Moderate to Severe Plaque-Type Psoriasis). ${ }^{30}$ Similar to studies in $\mathrm{CD}$, most reported adverse events with ustekinumab were mild and did not require treatment withdrawal. The long-term safety of ustekinumab was recently studied in a pooled analysis of psoriasis trials involving 1,852 patients exposed to ustekinumab for at least 1 year, 1,247 patients for at least 2 years, and 157 patients for at least 3 years. ${ }^{19,37,38}$ Common adverse events seen with longterm use were similar to those reported during the placebocontrolled period, and included headache, nasopharyngitis, and upper respiratory tract infections (Table 2). The most frequent serious adverse events reported with long-term use

Table 2 Commonly reported adverse effects in pooled clinical trials of ustekinumab

Nasopharyngitis

Upper respiratory tract infection

Headache

Fatigue were serious infections. Rates were similar between the placebo and $90 \mathrm{mg}$ groups and lower in the $45 \mathrm{mg}$ group (rates of 0.49 and 1.97 events per 100 patient-years in the $45 \mathrm{mg}$ and $90 \mathrm{mg}$ ustekinumab groups, respectively, compared to 1.70 in the placebo group). ${ }^{19,38}$ No cases of tuberculosis were reported..$^{37,38}$ The second-most common serious adverse events reported were cardiac in nature (rates of 0.8 and 1.3 events per 110 patient-years in the $45 \mathrm{mg}$ and $90 \mathrm{mg}$, ustekinumab groups, respectively). ${ }^{19}$ The incidence of malignancy (excluding nonmelanoma skin cancers) was comparable between patients exposed to ustekinumab and the general US population (rates of 0.7 and 0.5 events per 100 patient-years in the $45 \mathrm{mg}$ and $90 \mathrm{mg}$ ustekinumab groups, respectively). ${ }^{19,38}$

Most recently, results from a pooled analysis of four studies of ustekinumab in psoriasis followed safety data up to 5 years after treatment. ${ }^{39}$ As previously reported, no doserelated or cumulative toxicity was observed with increasing duration of ustekinumab administration for up to 5 years. ${ }^{39}$

In the Phase IIA ustekinumab study, 99 of 131 patients had serum samples available for assessment of ustekinumab antibodies. No anti-ustekinumab antibodies were identified in this study. ${ }^{24}$ In the Phase IIB ustekinumab study, 427 patients treated with ustekinumab had samples for analysis of immunogenicity. Three patients $(0.7 \%)$ had positive antibodies to ustekinumab through week $36 .{ }^{16}$ Higher rates of antibodies to ustekinumab were reported in the pooled data from four studies of ustekinumab in psoriasis, which comprised 3,117 patients treated with ustekinumab, ranging from $3.8 \%$ to $5.4 \% .{ }^{39}$ There are currently no data on the use of concurrent immunomodulators and the rate of antibody formation to ustekinumab.

\section{Patient-focused perspectives, such as quality of life, satisfaction, adherence, and update}

To date, there are no specific data available regarding QOL in patients with $\mathrm{CD}$ who are treated with ustekinumab. The effect of ustekinumab on health-related QOL was evaluated as a secondary end point in some psoriasis and psoriatic arthritis trials. ${ }^{19}$ In the clinical trials in patients with psoriasis, ustekinumab significantly improved healthrelated QOL, as assessed by the Dermatology Life Quality Index at 12 weeks. ${ }^{30,31}$ Work productivity, number of work days missed, symptoms of depression and anxiety, and sexual difficulties were also improved in the ustekinumabtreatment group. ${ }^{40-42}$ Improvements in health-related QOL were also seen in patients with psoriatic arthritis treated with ustekinumab. ${ }^{32}$ 
Table 3 Treatment end points from published studies of ustekinumab in Crohn's disease

\begin{tabular}{lll}
\hline & Induction & Maintenance \\
\hline $\begin{array}{l}\text { Clinical response - anti-TNF } \alpha \text {-naïve } \\
\begin{array}{l}\text { Clinical response }- \text { anti-TNF } \alpha- \\
\text { experienced }\end{array}\end{array}$ & Not significant & NA \\
$\begin{array}{l}\text { Clinical remission - anti-TNF } \alpha \text {-naïve } \\
\text { Clinical remission - anti-TNF } \alpha-\end{array}$ & Not significant & NA \\
$\begin{array}{l}\text { experienced } \\
\text { Mucosal healing }\end{array}$ & Not significant & Significant \\
Quality of life & NA & NA \\
\hline
\end{tabular}

Abbreviations: NA, not available; TNF, tumor necrosis factor.

\section{Conclusion}

\section{Potential place in therapy}

Currently, anti-TNF $\alpha$ antagonists are the most effective therapeutic options available for patients with $\mathrm{CD}$, and have the potential to induce and maintain steroid-free remission, promote mucosal healing, and modify the natural course of the disease. However, a significant proportion of patients do not respond adequately to these agents, and an additional subset of patients develop side effects that require changing to a different therapeutic class. Therefore therapies inhibiting inflammation through mechanisms other than TNF $\alpha$ blockade are needed.

IL-12 and IL-23 are important proinflammatory cytokines involved in the pathogenesis of $\mathrm{CD}$, and therefore targeting IL-12/23 should reduce proinflammatory cytokine production and reduce intestinal inflammation in this setting. Data from the published Phase II trials evaluating ustekinumab in $\mathrm{CD}$ are promising, and have shown that ustekinumab is effective in inducing clinical response and maintaining clinical response and clinical remission in moderate-to-severely active $\mathrm{CD}$ in patients with a prior inadequate response to anti$\mathrm{TNF} \alpha$ therapy. It is currently unclear whether ustekinumab is effective in CD patients naïve to anti-TNF $\alpha$ therapies. The only published study that included this patient population failed to meet its primary end point of clinical response. This study was limited by a high placebo-response rate (40\%) which limits the ability to detect a treatment effect for ustekinumab. Furthermore, a second anti-IL-12/23 antibody, briakinumab, was unable to show convincing clinical benefit in a similar $\mathrm{CD}$ patient population, ${ }^{43}$ and is no longer in clinical development. Therefore, while ustekinumab has shown benefit in patients with prior anti-TNF $\alpha$ exposure, it is not completely certain how ustekinumab will be placed in the treatment paradigm for $\mathrm{CD}$ or how effective it will be in anti-TNF $\alpha$-naïve patients (Table 3).

\section{Future role}

We suspect that ustekinumab will be shown to be effective at inducing and maintaining remission in patients with moderate-to-severely active $\mathrm{CD}$ with a prior inadequate response to anti-TNF $\alpha$ therapy. We also suspect that ustekinumab will be an appropriate first-line biologic option in patients with a contraindication to anti-TNF $\alpha$ agents, such as those with multiple sclerosis. It is currently unclear whether ustekinumab will be effective in patients naïve to anti-TNF $\alpha$ therapies. The results from Phase III trials of ustekinumab will help address these questions.

\section{Disclosure}

The authors report no conflicts of interest in this work.

\section{References}

1. Munkholm P, Langholz E, Davidsen M, Binder V. Frequency of glucocorticoid resistance and dependency in Crohn's disease. Gut. 1994;35(3):360-362.

2. Modigliani R, Mary JY, Simon JF, et al. Clinical, biological, and endoscopic picture of attacks of Crohn's disease. Evolution on prednisolone. Groupe d'Etude Thérapeutique des Affections Inflammatoires Digestives. Gastroenterology. 1990;98(4):811-818.

3. McDonald JW, Tsoulis DJ, Macdonald JK, Feagan BG. Methotrexate for induction of remission in refractory Crohn's disease. Cochrane Database Syst Rev. 2012;12:CD003459.

4. Pearson DC, May GR, Fick GH, Sutherland LR. Azathioprine and 6-mercaptopurine in Crohn disease. A meta-analysis. Ann Intern Med. 1995;123(2):132-142.

5. Sandborn W, Sutherland L, Pearson D, May G, Modigliani R, Prantera C. Azathioprine or 6-mercaptopurine for inducing remission of Crohn's disease. Cochrane Database Syst Rev. 2000;(2):CD000545.

6. Targan SR, Hanauer SB, van Deventer SJH, et al. A short-term study of chimeric monoclonal antibody cA2 to tumor necrosis factor alpha for Crohn's disease. N Engl J Med. 1997;337(15):1029-1035.

7. Hanauer SB, Feagan BG, Lichtenstein GR, et al. Maintenance infliximab for Crohn's disease: the ACCENT I randomised trial. Lancet. 2002;359(9317):1541-1549.

8. Hanauer SB, Sandborn WJ, Rutgeerts P, et al. Human anti-tumor necrosis factor monoclonal antibody (adalimumab) in Crohn's disease: the CLASSIC-I trial. Gastroenterology. 2006;130(2):323-332.

9. Colombel JF, Sandborn WJ, Rutgeerts P, et al. Adalimumab for maintenance of clinical response and remission in patients with Crohn's disease: the CHARM trial. Gastroenterology. 2007;132(1):52-65.

10. Sandborn WJ, Feagan BG, Stoinov S, et al. Certolizumab pegol for the treatment of Crohn's disease. N Engl J Med. 2007;357(3):228-238.

11. Schreiber S, Khaliq-Kareemi M, Lawrance IC, et al. Maintenance therapy with certolizumab pegol for Crohn's disease. $N$ Engl J Med. 2007;357(3):239-250.

12. Behm BW, Bickston SJ. Tumor necrosis factor-alpha antibody for maintenance of remission in Crohn's disease. Cochrane Database Syst Rev. 2008;(1):CD006893.

13. Colombel JF, Sandborn WJ, Reinisch W, et al. Infliximab, azathioprine, or combination therapy for Crohn's disease. N Engl J Med. 2010;362(15):1383-1395.

14. Lowenberg M, D'Haens G. Novel targets for inflammatory bowel disease therapeutics. Curr Gastroenterol Reports. 2013;15(2):311.

15. Sandborn WJ, Abreu MT, D'Haens G, et al. Certolizumab pegol in patients with moderate to severe Crohn's disease and secondary failure to infliximab. Clin Gastroenterol Hepatol. 2010;8(8):688-695. e2. 
16. Sandborn WJ, Gasink C, Gao LL, et al. Ustekinumab induction and maintenance therapy in refractory Crohn's disease. $N$ Engl J Med. 2012;367(16):1519-1528.

17. Trinchieri G, Pflanz S, Kastelein RA. The IL-12 family of heterodimeric cytokines: new players in the regulation of T cell responses. Immunity. 2003;19(5):641-644.

18. Gee K, Guzzo C, Che Mat NF, Ma W, Kumar A. The IL-12 family of cytokines in infection, inflammation and autoimmune disorders. Inflamm Allergy Drug Targets. 2009;8(1):40-52.

19. Toussirot E, Michel F, Béreau M, Binda D. Ustekinumab in chronic immune-mediated diseases: a review of long term safety and patient improvement. Patient Prefer Adherence. 2013;7:369-377.

20. Mannon PJ, Fuss IJ, Mayer L, et al. Anti-interleukin-12 antibody for active Crohn's disease. N Engl J Med. 2004;351(20):2069-2079.

21. Peluso I, Pallone F, Monteleone G. Interleukin-12 and Th1 immune response in Crohn's disease: pathogenetic relevance and therapeutic implication. World J Gastroenterol. 2006;12(35):5606-5610.

22. Neurath MF. IL-23: a master regulator in Crohn disease. Nat Med. 2007;13(1):26-28.

23. Duerr RH, Taylor KD, Brant SR, et al. A genome-wide association study identifies IL23R as an inflammatory bowel disease gene. Science. 2006;314(5804):1461-1463.

24. Oppmann B, Lesley R, Blom B, Timans JC, Xu Y, Hunte B, et al. Novel p19 protein engages IL-12p40 to form a cytokine, IL-23, with biological activities similar as well as distinct from IL-12. Immunity. 2000;13(5):715-725.

25. Iwakura Y, Ishigame H. The IL-23/IL-17 axis in inflammation. J Clin Invest. 2006;116(5):1218-1222.

26. Sandborn WJ, Feagan BG, Fedorak RN, et al. A randomized trial of ustekinumab, a human interleukin-12/23 monoclonal antibody, in patients with moderate-to-severe Crohn's disease. Gastroenterology. 2008;135(4):1130-1141

27. Toussirot E. The IL23/Th17 pathway as a therapeutic target in chronic inflammatory diseases. Inflamm Allergy Drug Targets. 2012;11(2): 159-168.

28. Croxtall JD. Ustekinumab: a review of its use in the management of moderate to severe plaque psoriasis. Drugs. 2011;71(13):1733-1753.

29. Krueger GG, Langley RG, Leonardi C, et al. A human interleukin-12/23 monoclonal antibody for the treatment of psoriasis. $N$ Engl J Med. 2007;356(6):580-592.

30. Leonardi CL, Kimball AB, Papp KA, et al. Efficacy and safety of ustekinumab, a human interleukin-12/23 monoclonal antibody, in patients with psoriasis: 76-week results from a randomised, doubleblind, placebo-controlled trial (PHOENIX 1). Lancet. 2008;371(9625): 1665-1674.

31. Papp KA, Langley RG, Lebwohl M, et al. Efficacy and safety of ustekinumab, a human interleukin-12/23 monoclonal antibody, in patients with psoriasis: 52-week results from a randomised, doubleblind, placebo-controlled trial (PHOENIX 2). Lancet. 2008;371(9625): 1675-1684.

32. Gottlieb A, Menter A, Mendelsohn A, et al. Ustekinumab, a human interleukin 12/23 monoclonal antibody, for psoriatic arthritis: randomised, double-blind, placebo-controlled, crossover trial. Lancet. 2009;373(9664):633-640.
33. McInnes IB, Kavanaugh A, Gottlieb AB, et al. Efficacy and safety of ustekinumab in patients with active psoriatic arthritis: 1 year results of the phase 3, multicentre, double-blind, placebo-controlled PSUMMIT 1 trial. Lancet. 2013;382(9894):780-789.

34. Janssen Research and Development, LLC. A Study to Evaluate the Safety and Efficacy of Ustekinumab in Patients With Moderately to Severely Active Crohn's Disease Who Have Failed or Are Intolerant to Tumor Necrosis Factor (TNF) Antagonist Therapy (UNITI-1). Available from: http:/clinicaltrials.gov/ct2/show/NCT01369329. NLM identifier: NCT01369329. Accessed March 6, 2014.

35. Janssen Research and Development, LLC. A Study to Evaluate the Safety and Efficacy of Ustekinumab Induction Therapy in Patients With Moderately to Severely Active Crohn's Disease (UNITI-2). Available from: http:/clinicaltrials.gov/ct2/show/NCT01369342. NLM identifier: NCT01369342. Accessed March 6, 2014.

36. Janssen Research and Development, LLC. A Study to Evaluate the Safety and Efficacy of Ustekinumab Maintenance Therapy in Patients With Moderately to Severely Active Crohn's Disease (IM-UNITI) Available from: http://clinicaltrials.gov/ct2/show/NCT01369355. NLM identifier: NCT01369355. Accessed March 6, 2014.

37. Lebwohl M, Leonardi C, Griffiths CE, et al. Long-term safety experience of ustekinumab in patients with moderate-to-severe psoriasis (part I of II): results from analyses of general safety parameters from pooled Phase 2 and 3 clinical trials. J Am Acad Dermatol. 2012;66(5): 731-741.

38. Gordon KB, Papp KA, Langley RG, et al. Long-term safety experience of ustekinumab in patients with moderate to severe psoriasis (part II of II): results from analyses of infections and malignancy from pooled phase II and III clinical trials. J Am Acad Dermatol. 2012;66(5): 742-751.

39. Papp KA, Griffiths CE, Gordon K, et al. Long-term safety of ustekinumab in patients with moderate-to-severe psoriasis: final results from 5 years of follow-up. Br J Dermatol. 2013;168(4):844-854.

40. Reich K, Schenkel B, Zhao N, et al. Ustekinumab decreases work limitations, improves work productivity, and reduces work days missed in patients with moderate-to-severe psoriasis: results from PHOENIX 2. J Dermatol Treat. 2011;22(6):337-347.

41. Langley RG, Feldman SR, Han C, et al. Ustekinumab significantly improves symptoms of anxiety, depression, and skin-related quality of life in patients with moderate-to-severe psoriasis: results from a randomized, double-blind, placebo-controlled phase III trial. J Am Acad Dermatol. 2010;63(3):457-465.

42. Guenther L, Han C, Szapary P, et al. Impact of ustekinumab on health-related quality of life and sexual difficulties associated with psoriasis: results from two phase III clinical trials. J Am Acad Dermatol. 2011;25(7):851-857.

43. Panniccione R, Sandborne W, Gordon G, et al. Briakinumab (ABT874) for treatment of Crohn's disease. Late breaking abstract presented at: 18th United European Gastroenterology Week (UEWG); October 23-27; 2010; Barcelona, Spain. Abstract OP051D.
Clinical and Experimental Gastroenterology

\section{Publish your work in this journal}

Clinical and Experimental Gastroenterology is an international, peerreviewed, open access journal, publishing all aspects of gastroenterology in the clinic and laboratory, including: Pathology, pathophysiology of gastrointestinal disease; Investigation and treatment of gastointes tinal disease; Pharmacology of drugs used in the alimentary tract;

\section{Dovepress}

Immunology/genetics/genomics related to gastrointestinal disease. This journal is indexed on CAS. The manuscript management system is completely online and includes a very quick and fair peer-review system. Visit http://www.dovepress.com/testimonials.php to read real quotes from published authors. 